\title{
Sorg som diagnose
}

\author{
I forbindelse med revisjon av diagnosemanualene ICD-10 og DSM-IV er det blitt fremmet et forslag om en \\ egen diagnose for sorg etter dødsfall hos nærstående. Forslaget har møtt betydelig motstand, bl.a. fordi \\ man frykter sykeliggjøring av normal sorg. Tilhengerne hevder at det blir lettere å fange opp dem som strever \\ med sorgen slik at de kan få adekvat behandling.
}

Pål Kristensen

pal.kristensen@sthf.no

Sorg er en naturlig og forventet reaksjon på å miste en nærstående. Det har imidlertid lenge vært beskrevet at sorg etter dødsfall også kan føre til sykdom. Ingen av klassifikasjonssystemene for psykiske lidelser, Diagnostic and Statistical Manual of Mental Disorders (DSM) eller International Classification of Diseases (ICD), har så langt hatt en egen diagnose for sorg.

Fra 1990-årene er det blitt gjennomført et systematisk forskningsarbeid i et forsøk på å enes om et forslag til en egen sorgdiagnose. Foregangspersoner har vært de amerikanske psykiaterne Mardi Horowitz og Katherine Shear og, ikke minst, epidemiologen Holly Prigerson. Også fagmiljøer i Europa, bl.a. i Sveits, Nederland og Norge, har vært engasjert. Det har vært flere forslag til betegnelse, som «traumatisk sorg», «komplisert sorg» og «forlenget sorg-forstyrrelse».

I DSM-5, som skal være ferdig i 2013, er det nå et konkret forslag om sorg som underkategori av tilpasningsforstyrrelser. Forslaget i ICD-11, som skal komme i 2015, er at «forlenget sorg-forstyrrelse» kategoriseres som en egen diagnose under stressrelaterte forstyrrelser (1). Til tross for ulike navn er kriteriene i hovedsak de samme i ICD-11 og DSM-5. I denne artikkelen har jeg valgt å bruke betegnelsen «forlenget sorg-forstyrrelse».

Hva er forlenget sorg-forstyrrelse? Sorg betraktes av mange i dag som et kontinuum fra normal til unormal eller patologisk sorg (2). Det er med andre ord intensiteten og varigheten av symptomene, i tillegg til graden av funksjonstap, som avgjør om sorgen kan betraktes som patologisk.

Kjernesymptomet ved forlenget sorg-forstyrrelse er separasjonsubehag. Dette manifesteres i form av intens og vedvarende lengsel etter avdøde, følelsesmessig smerte eller overopptatthet av avdøde og/eller omstendighetene omkring dødsfallet $(3,4)$.
I tillegg er det vansker med å godta dødsfallet, sinne/bitterhet, unngåelse av det som kan påminne om avdøde, vansker med å gå videre i livet, endret identitetsfølelse, følelsen av at livet er tomt og meningsløst, vansker med å planlegge fremtiden eller ta del i aktiviteter eller relasjoner. Kort fortalt kan man betegne forlenget sorg-forstyrrelse som en form for kronisk sorg. Tilstanden karakteriseres ofte som «å stå fast» i sorgen (5).

Mens man i forslaget til ICD-11 påpeker at symptomene må vedvare utover seks måneder etter tapet (1), er man i forslaget til DSM-5 mer konservativ og beskriver at symptomene må vare utover 12 måneder (seks måneder hos barn). Et vesentlig kriterium i både ICD-11 og DSM-5 er at symptomene må føre til funksjonstap i hverdagen. Det understrekes også at sorgreaksjonene må være ute av proporsjon i henhold til kulturelle, religiøse eller aldersadekvate normer.

Man regner med at ca. $7-10 \%$ av dem som mister sine nære, utvikler forlenget sorg-forstyrrelse, men betydelig høyere tall er påvist hos foreldre som har mistet et barn og hos etterlatte etter brå, voldsom død (6-9). Ved forlenget sorg-forstyrrelse er det høy komorbiditet med andre psykiske lidelser (3), men anslagsvis 30-50\% vil kun vise symptomer på forlenget sorg-forstyrrelse $(9,10)$.

\section{Forskningen bak forslaget om en sorgdiagnose}

For å kunne defineres som en psykisk lidelse må det foreligge et atferdsmessig eller psykologisk syndrom eller mønster som opptrer hos et individ og som fører til klinisk signifikant ubehag eller funksjonssvikt (11). Videre må dette ikke være en forventet reaksjon eller en kulturelt akseptert reaksjon på en spesiell hendelse. Symptomene skal kunne differensieres fra symptomene ved andre psykiske lidelser og ha diagnostisk validitet når det gjelder distinkte risikofaktorer, prognose og behandlingsrespons.

Studier har vist at det å oppfylle kriteriene for forlenget sorg-forstyrrelse utover seks måneder etter tap av nærstående pre- dikerer langvarige fysiske og/eller psykiske plager som hjerteproblemer, immunologisk dysfunksjon, hypertensjon, depresjon, suicidaltanker, redusert livskvalitet og økt forbruk av tobakk og alkohol, uavhengig av andre psykiske lidelser $(3,4)$. Økt forekomst av søvnvansker, hyppigere legebesøk, sykmeldinger og sykehusinnleggelser er også påvist (12).

Faktoranalytiske studier har vist at symptomene er delvis overlappende med, men også forskjellige fra depresjon, angst og posttraumatisk stresslidelse (3). Det er først og fremst intens og vedvarende lengsel som skiller forlenget sorg-forstyrrelse fra de nærmeste «diagnostiske naboene». Forlenget sorg-forstyrrelse innebærer distinkte risikofaktorer sammenliknet med andre psykiske lidelser (13) og kan knyttes til økt aktivering av hjernens belønningssenter, nucleus accumbens (14). Forlenget sorg-forstyrrelse er ikke bare et vestlig fenomen, det er også påvist i Pakistan, Japan, Kina, Rwanda, Israel og Iran (4).

Også norske forskere har gjort funn som støtter forslaget om innføring av en sorgdiagnose. Kristensen og medarbeidere fant i sin studie av etterlatte to år etter tsunamikatastrofen i 2004 at det å oppfylle kriterier for forlenget sorg-forstyrrelse var forbundet med funksjonstap, uavhengig av depresjon og posttraumatisk stresslidelse (9). Mens effektive psykologiske behandlingsformer mot depresjon, som interpersonlig terapi, har vist seg å ha lav respons i behandling av forlenget sorg-forstyrrelse, har intervensjoner rettet mot kjernevanskene vist seg å være mer virksomme $(15,16)$.

\section{Fordeler og ulemper}

Det er liten tvil om at forslaget om å innføre en egen sorgdiagnose er blitt møtt med betydelig skepsis. Det sterkeste argumentet mot innføringen er frykten for sykeliggjøring og «medikalisering» av normal sorg (17). Den amerikanske sosiologen Jerome Wakefield hevder at symptomene på forlenget sorg-forstyrrelse ikke er distinkt forskjellige fra normale sorgreaksjoner og at man ikke har klart å skille tilstanden godt nok fra intens normal sorg, der tilhelings- 


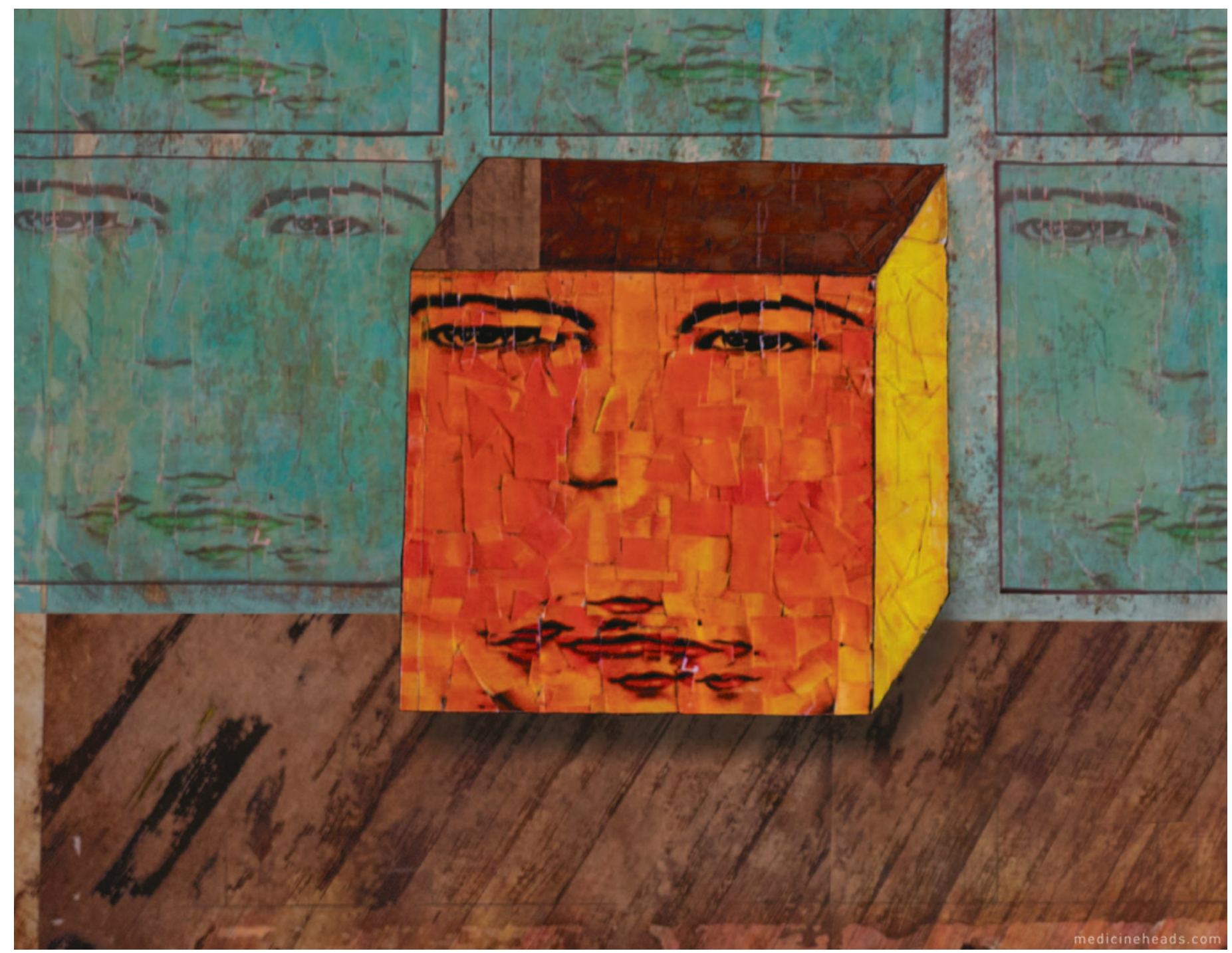

Illustrasjon $\odot$ Trond Nordahl/medicineheads

forløpet skjer gradvis over lang tid (18). Wakefield mener at forskningen på forlenget sorg-forstyrrelse ikke samsvarer med nyere kunnskap om hvor lang tid en normal sorgprosess kan ta, og at det vil føre til mange falskt positive.

Det er selvfølgelig viktig å anerkjenne at man kan ha en intens og langvarig sorg uten at den i seg selv kan karakteriseres som unormal, en sorg som ikke kan akselereres eller «helbredes» av behandling. Det er også fare for stigmatisering og at man blir stemplet som syk når man er $\mathrm{i}$ dyp sorg. Andre frykter at det sosiale nettverk i verste fall kan trekke seg mer tilbake når det blir økt vekt på behandling av sorg, men det finnes lite forskningsmessig belegg for denne påstanden (13).

Tilhengere hevder at innføring av en sorgdiagnose vil føre til at det blir lettere å fange opp dem som strever med sorgen slik at de kan få mer tilpasset hjelp og støtte (13). Således kan innføring av en sorgdiagnose ha klinisk nytteverdi. Med dagens praksis vil de som står fast i sorgen kunne få ulike diagnoser som ikke nødvendigvis er adekvate for det de sliter med. En nyere dansk studie viste at informasjon til fastleger om forlenget sorg-forstyrrelse kan gjøre at de lettere gjenkjenner tilstanden, dermed vil det ha positiv innvirkning på det videre behandlingsforløp (19). Innføring av en sorgdiagnose vil dessuten kunne utløse mer midler til forskning innenfor viktige områder som risikofaktorer, forebygging og behandling. Diagnoser gir også visse rettigheter når det gjelder tilgang til behandling, sykmelding og sosial kompensasjon.

Sist, men ikke minst - det hevdes at en sorgdiagnose ikke bare kan gi økt kunnskap hos dem som skal hjelpe mennesker i sorg, den kan også være til hjelp for dem som er rammet. Den kjente psykiater og sorgforsker Colin M. Parkes hevder at de som strever med sorgen, kan få større anerkjennelse for det de går igjennom, økt forståelse for hva forlenget sorg-forstyrrelse er og en bekreftelse på at det er mulig å få hjelp (20). Dette 
støttes av en studie fra USA (21). Det finnes imidlertid lite annen forskning på området.

Det er fortsatt flere spørsmål knyttet til innføringen av en sorgdiagnose, bl.a. hvordan man forholder seg til andre undergrupper av patologisk sorg (22). Hovedvekten har så langt vært lagt på forlenget sorg med intenst separasjonsubehag, mens andre varianter som traumatisk sorg, der påtrengende minner/tanker fra et dramatisk dødsfall stenger for forløsning av normal sorg, og utsatt eller forsinket sorg ikke anerkjennes på samme måte. Disse subtypene er klinisk interessante og vil kunne ha andre behandlingsmessige utfordringer enn forlenget sorgforstyrrelse. Forslag om en egen sorgdiagnose vil heller ikke kunne påvirke dagens praksis, f.eks. ved spørsmål om sykmelding av sørgende før det er gått seks måneder etter et tap, selv for dem med intense sorgreaksjoner og betydelig funksjonssvikt.

Det er videre nødvendig å se kritisk på om kriteriene er egnet til å beskrive barns og unges sorg. Selv om forlenget sorgforstyrrelse også er beskrevet hos disse aldersgruppene (23), er det et faktum at mange barn har større vansker med følelsesregulering enn voksne, noe kan føre til mer unnvikelse av tanker og følelser (24). Utviklingsperspektivet er med andre ord sentralt for å forstå hvordan barn mestrer tap og sorg, og noen tilpasninger er foreslått i DSM-5 (25).

Det sterke savnet som kan kjennetegne sorgen etter tap av nærstående kan være like dominerende etter andre typer tap, og det er uklart hvorfor det skulle være så prinsipielt forskjellig å sørge etter et dødsfall som etter tap av jobb, funksjon, helse, ektefelle ved skilsmisse osv. En studie etter orkanen «Katrina» viste at ikke bare tap av nærstående ved død, men også andre typer tap (bl.a. arbeid og økonomi) hadde sammenheng med forlenget sorg-forstyrrelse (26).

Innføringen av en sorgdiagnose kan få visse praktiske implikasjoner. I praksis er det trolig slik at mange som strever med sorg, allerede er i kontakt med hjelpeapparatet. Det er også studier som viser at mange med forlenget sorg-forstyrrelse ikke søker hjelp (27). Innføring av en sorgdiagnose kan med andre ord gi økt oppmerksomhet omkring behovet for og rettigheter til behandling, noe som kan bli en utfordring for et allerede presset helsevesen.

\section{Konklusjon}

Det er allment kjent at sorg kan føre til sykdom. Det er viktig ut fra et klinisk og forskningsmessig synspunkt å studere de helseproblemene som kan følge av sorg og tap etter dødsfall. Nye diagnoser bør imid- lertid kun innføres hvis det er strengt nødvendig, og mange er bekymret for overdiagnostisering og overbehandling av normal sorg, siden skillet mellom normal og patologisk sorg kan virke noe uklart. Dog mener jeg at det er forskningsmessig godt dokumentert at vedvarende og intens lengsel i etterkant av tap av nærstående ikke er det samme som depresjon eller angst, men representerer et distinkt syndrom som kan få betydelige fysiske og psykiske følger og som kan behandles. Jeg mener derfor at fordelene ved innføring av diagnosen synes å veie opp for ulempene.

Artikkelen er basert på prøveforelesning for doktorgraden ved Institutt for klinisk medisin, Det medisinske fakultet, Universitetet i Oslo, 25.6. 2012

Jeg takker mine gode kolleger Lars Weisæth, Trond Heir og Ajmal Hussain for nyttige kommentarer til denne artikkelen.

\section{Pål Kristensen (f. 1963)}

er psykologspesialist og jobber ved Barneog ungdomspsykiatrisk seksjon, Sykehuset Telemark. Han er også forsker ved Nasjonalt kunnskapssenter om vold og traumatisk stress (NKVTS) og tok i 2012 doktorgraden på sorg etter tsunamikatastrofen i 2004 og Vassdalenulykken i 1986.

Forfatter har fylt ut ICMJE-skjemaet og oppgir ingen interessekonflikter.

\section{Litteratur}

1. Maercker A, Brewin CR, Bryant RA et al. Classification and definition of disorders specifically associated with stress: new proposals and implication for ICD-11. Lancet 2013; akseptert for publisering.

2. Holland JM, Neimeyer RA, Boelen PA et al. The underlying structure of grief: a taxonomic investigation of prolonged and normal reactions to loss. J Psychopathol Behav Assess 2008: 31: 190-201.

3. Prigerson HG, Horowitz MJ, Jacobs SC et al. Prolonged grief disorder: Psychometric validation of criteria proposed for DSM-V and ICD-11. PLoS Med 2009; 6: e1000121.

4. Shear MK, Simon N, Wall M et al. Complicated grief and related bereavement issues for DSM- 5 . Depress Anxiety 2011; 28: 103-17.

5. Prigerson HG. Complicated grief: when the path of adjustment leads to a dead end. Bereavement Care 2004; 23: 38-40

6. Kristensen P, Weisæth L, Heir T. Predictors of complicated grief after a natural disaster: a population study two years after the 2004 South-east Asian Tsunami. Death Stud 2010: 34: 137-50.

7. Dyregrov K, Nordanger D, Dyregrov A. Predictors of psychosocial distress after suicide, SIDS and accidents. Death Stud 2003; 27: 143-65.

8. Kristensen P. Weisæth L, Heir T. Bereavement and mental health after sudden and violent losses: a review. Psychiatry 2012; 75: 76-97.

9. Kristensen P. Weisæth L, Heir T. Psychiatric dis orders among disaster bereaved: an interview study of individuals directly or not directly exposed to the 2004 tsunami. Depress Anxiety 2009; 26: 1127-33
10. Morina N, Rudari V, Bleichhardt G et al. Prolonged grief disorder, depression, and posttraumatic stress disorder among bereaved Kosovar civilian war survivors: a preliminary investigation. Int J Soc Psychiatry 2010: 56: 288-97.

11. Stein DJ, Phillips KA, Bolton D et al. What is a mental/psychiatric disorder? From DSM-IV to DSM-V. Psychol Med 2010; 40: 1759-65.

12. Lannen PK, Wolfe J, Prigerson HG et al. Unresolved grief in a national sample of bereaved parents: impaired mental and physical health 4 to 9 years later. J Clin Oncol 2008; 26: 5870-6.

13. Lichtenthal WG, Cruess DG, Prigerson HG. A case for establishing complicated grief as a distinct mental disorder in DSM-V. Clin Psychol Rev 2004 24: $637-62$

14. O'Connor MF, Wellisch DK, Stanton AL et al. Craving love? Enduring grief activates brain's reward center. Neuroimage 2008; 42: 969-72.

15. Shear KM, Frank E, Houck PR et al. Treatment of complicated grief: a randomized controlled trial. JAMA 2005; 293: 2601-8.

16. Wittouck C, Van Autreve S, De Jaegere E et al. The prevention and treatment of complicated grief: a meta-analysis. Clin Psychol Rev 2011; 31: 69-78.

17. Stroebe M, van Son M, Stroebe W et al. On the classification and diagnosis of pathological grief. Clin Psychol Rev 2000; 20: 57-75.

18. Wakefield JC. Should prolonged grief be reclassified as a mental disorder in DSM-5?: reconsidering the empirical and conceptual arguments for complicated grief disorder. J Nerv Ment Dis 2012; 200: 499-511.

19. Guldin M-B, Vedsted P, Jensen AB et al. Bereavement care in general practice: a cluster-randomized clinical trial. Fam Pract 2012. E-publisert 10.9.2012.

20. Parkes CM. Complicated grief: the debate over a new DSM-V diagnostic category. I: Doka KJ, red. Living with grief: before and after the death. Washington D.C.: Hospice Foundation of America 2007: 139-52

21. Johnson JG, First MB, Block S et al. Stigmatization and receptivity to mental health services among recently bereaved adults. Death Stud 2009; 33: $691-711$.

22. Rando TA, Doka KJ, Fleming $S$ et al. A call to the field: complicated grief in the DSM-5. Omega (Westport) 2012; 65: 251-5.

23. Spuij M, Reitz E, Prinzie P et al. Distinctiveness of symptoms of prolonged grief, depression, and post-traumatic stress in bereaved children and adolescents. Eur Child Adolesc Psychiatry 2012 21: 673-9.

24. Dyregrov A, Dyregrov K. Complicated grief in children. I: Stroebe M. Schut H van den Bout J, red. Complicated grief. Scientific foundations for health care professionals. New York, NY: Routledge, 2012: 68-82

25. Kaplow JB, Layne CM, Pynoos RS et al. DSM-V diagnostic criteria for bereavement-related disorders in children and adolescents: developmenta considerations. Psychiatry 2012; 75: 243-66.

26. Shear MK, McLaughlin KA, Ghesquiere A et al. Complicated grief associated with hurricane Katrina. Depress Anxiety 2011; 28: 648-57.

27. Lichtenthal WG, Nilsson M, Kissane DW et al. Underutilization of mental health services among bereaved caregivers with prolonged grief disorder Psychiatr Serv 2011; 62: 1225-9.

Mottatt 3.1. 2013, første revisjon innsendt 25.2. 2013, godkjent 14.3. 2013. Medisinsk redaktør Siri Lunde. 